\title{
Tourism, Water Pollution, and Waterway Landscape Changes in a Traditional Village in the Huizhou Region, China
}

\author{
Pinyu Chen ${ }^{1,2}$, Yizheng Zhao ${ }^{1,2}$, Di Zuo ${ }^{1,2}$ and Xiang Kong ${ }^{1,2, *}$ \\ 1 The Center for Modern Chinese City Studies, East China Normal University, Shanghai 200062, China; \\ 52183902008@stu.ecnu.edu.cn (P.C.); 52193902010@stu.ecnu.edu.cn (Y.Z.); \\ 52163902009@stu.ecnu.edu.cn (D.Z.) \\ 2 School of Urban and Regional Science, East China Normal University, Shanghai 200241, China \\ * Correspondence: xkong@bs.ecnu.edu.cn
}

Citation: Chen, P.; Zhao, Y.; Zuo, D.; Kong, X. Tourism, Water Pollution, and Waterway Landscape Changes in a Traditional Village in the Huizhou Region, China. Land 2021, 10, 795. https://doi.org/10.3390/land10080795

Academic Editor: Andrew Millington

Received: 17 May 2021

Accepted: 26 July 2021

Published: 29 July 2021

Publisher's Note: MDPI stays neutral with regard to jurisdictional claims in published maps and institutional affiliations.

Copyright: (c) 2021 by the authors. Licensee MDPI, Basel, Switzerland. This article is an open access article distributed under the terms and conditions of the Creative Commons Attribution (CC BY) license (https:// creativecommons.org/licenses/by/ $4.0 /)$.

\begin{abstract}
Based on archival research, non-participatory observation, and semi-structured interviews, this paper examined waterway landscape changes mainly caused by tourism development in Hongcun, a traditional village in the Huizhou region, China, and how the locals have responded to water pollution in order to achieve landscape sustainability. It is found that the physical structure of the waterways of Hongcun Village has been well preserved, but the water pollution caused by tourism, with a combination of changes of land use and demographic structure, has changed the functions and cultural meanings of waterways. Although there remains quite a daunting task towards sustainability in terms of technology, heritage protection, and desire for development, we claim the waterways environmental governance in which local governments play a crucial role in resilience strategies by controlling the sewage from homestays, restaurants, and pigment sewage from sketches. However, the ways in which landscape animates, including the daily lives, processual daily practices, and mundane activities of different social actors related to waterways, deserve further implementation to build the resilience of cultural landscape from the perspective of non-representational theory. This paper adds to a new narrative to the waterway landscape research by presenting a water utilization pattern that could profitably coexist with a specific environment in the Huizhou region in the agricultural society of ancient China and discussing how the non-representational theory contributes to analyzing and managing waterway landscapes in modern times. It also sheds light on the connection between cultural landscape and resilience.
\end{abstract}

Keywords: waterway landscape; cultural landscape; representation; non-representational theory; sustainability; resilience; Hongcun Village

\section{Introduction}

In the context of a constantly changing world, tourism constitutes one of the most significant contemporary forces of local change. Britton asserts that "tourism is one of the most important elements in the shaping of popular consciousness of places and in determining the creation of social images of those places ... tourism is an 'intense case' of how modern society orders relations between peoples and places" [1], which indicates that both the tangible and intangible aspects of a place can evidently be shaped by tourism. Due to its imageability and tangibility, tourism also generates a noticeable impact on landscapes, making landscapes a valuable means of analyzing geographical changes through tourism [2]. Therefore, tourism and landscape are related [3]. The rising locales of featuring therapeutic landscapes along with the health tourism boom [4]; a massive transformation of the environment into resort hotel landscape catalyzed by tourism [5,6]; the reorganization of border landscapes, and the dissolution of mental boundaries influenced by tourism [7] all highlight the complex interrelationships between the tourism phenomenon and the construction, reconstruction, and consumption of landscapes $[2,8]$. 
Tourism is closely associated with water. Water can be a central attraction, providing a means of transportation for some significant tourist activities and support for tourists' and residents' health in certain destinations [9]. Nevertheless, in most studies of landscapes in the social sciences in general, and tourism studies or cultural geography in particular, inland waterway landscapes are seldom discussed $[10,11]$. While the water changes in tourism have attracted some attention from political ecologists, they criticize the power relations behind water conflicts and social inequality from the perspective of political economy or post-structuralism [12,13]. Here, a waterway landscape is defined not merely as a result of human activity; it is both a material thing and a conceptual framing of the world [14]. Of particular relevance to this paper are the four sets of literature that examine human perceptions and reactions to various waterscapes associated with tourist activity [15-17], the role of rivers/lakes/water in the modern tourism industry around the world [18,19], guidebooks as traveling landscape-objects in waterways [20], and the multiple ecological, social, and cultural frames that have shaped waterscapes [21]. Thus far, few have examined the impact that tourism has had on inland waterway landscapes from the perspective of cultural geography, not to mention the related governance and sustainability. However, this deserves further research, as it uniquely links the cultural and the natural and is significant in terms of cultural, political, and social history.

Especially in the wake of the COVID-19 pandemic, the global tourism industry has all but ground to a halt, which has made tourist destinations face intertwined problems, such as a decrease in the number of tourists, ecological restoration, and community reconstruction, leading to an invaluable opportunity to rethink sustainable tourism development in terms of the environment, economy, and community. For example, the social media for the water city, Venice, which has been criticized for overtourism, has shown clear and undisturbed canals, shoals of fish visible in the turquoise shallows, swans gliding by, and dolphins re-entering the city during the pandemic [22]. Regardless of the veracity of such images, a destination that has been constantly under environmental distress in the past is undergoing a process of 'healing' [22]. To create a sustainable landscape for tourism and adapt to the post COVID-19 era, recasting host communities, incorporating indigenous values, and rethinking destinations and their functions have been on the agenda [23-25]. Rather than replacing materiality with symbols, the non-representational theory calls for returning to materiality per se and emphasizes attention to doings, practices, performances, the non-human, and lifeworlds, which are instructive in relation to the resilience of landscapes and destinations [26].

Thus, this paper aims to address this gap by examining the intersection of tourism, waterway landscape changes, and sustainability within discussions of representation/nonrepresentational theory. The main question guiding this research is: how does water pollution caused by tourism affect waterway landscape changes? What are the experiences and difficulties in water pollution control and sustainable development for the waterway landscapes, especially in non-Western developing countries? The case of Hongcun Village in Huangshan city, China, is used to illustrate the process of waterway landscape changes and governance. By a geo-historical theoretical examination, we address the heavily euro-centric framing of waterscapes that focuses more on industrial society and the representational aspects of waterways. We then attempt to put water in the center of the analysis to rethink its adaptability and resilience, in response to Visentin's recent call for a 'watery turn' in the humanities and social sciences [27]. Furthermore, different from the traditional quantitative methods for analyzing water body changes [10], based on an overall collaborative thinking framework of representation and non-representational theory, this paper provides a subtle approach to examine the cultural changes of waterway landscapes and the sustainability of cultural landscapes.

Hongcun Village is chosen as a case study as it is the most popular tourist destination in the Huizhou region, whose culture is the most representative and renowned among the three distinctive regional cultures in China. It is especially famous for its waterway landscape, which carries the geomancy culture, offering major water endowments of 
compelling beauty. Since Hongcun Village was listed as a world cultural heritage site in 2000, tourism has developed rapidly. However, water pollution issues have followed, which has altered people's lives and brought great changes for the waterway landscape. Nowadays, the governance programs to deal with water pollution and sustainable tourism development have been implemented. As a case, Hongcun Village is rather representative, in that it reflects the opportunities and challenges of traditional Chinese villages confronting significant changes in the local waterway landscape due to tourism development and socioeconomic transformation.

This paper begins by reviewing the cultural landscape and building a framework for an empirical analysis of the waterway landscape changes and governance. After a description of the fieldwork, we then provide qualitative evidence of how tourism development has had an impact on the waterway landscape changes in Hongcun Village, and we discuss how this impact is manifested and how the local governments and communities have responded to water pollution issues to achieve landscape sustainability. In the discussion and conclusion sections, the non-representational aspects of Hongcun Village's waterways, as a cultural landscape, are emphasized, and we illustrate the contributions of this study to the existing waterway/cultural landscape literature.

\section{Analyzing Waterway Landscapes: The Lens of Representation and Non-Representational Theory}

The landscape is a contested concept, of which there is no common understanding in geography. Traditionally, the physical sciences have defined a landscape as a measurable part of the land or environment, while human geography focuses on how it is constructed and produced by human interaction with the environment [28]. More often, the landscape in human geography refers to a cultural landscape. Sauer takes the landscape as the center of geographic research and directs the development of early cultural geography. In his seminal work, cultural landscape is defined as the product of human beings transforming a natural landscape under the guidance of "culture" [29]. Drawing on the arguments of Cosgrove [30], Brox [31], Terkenli [2,32], and Pitkänen [33], at least three different approaches have been proposed for landscape study in human geography.

The first is the physical approach, which considers a landscape as a spatial unit. Influenced by traditional cultural geography, the landscape is classified, analyzed, and assessed using land-use mapping and other quantitative methodologies, according to regional differences, property types, or the natural environment's characteristics [2]. The second is the cultural approach, which maintains that a landscape is a kind of socially constructed space. Influenced by new cultural geography, researchers emphasize that a landscape is a collection of symbols with a specific ideology. Landscape analysis should involve cultural values and cultural processes to uncover how the social meanings, ideas, and values create the landscape [31]. The third is the experiential approach, which claims that a landscape is a way of being. Influenced by humanistic geography, scholars interpret landscapes in a more comprehensive way, which regards them as corporeal and mental phenomena created through people's minds as a reflection of different sensory observations. They focus on individuals' feelings, experiences, and encounters on landscapes [33]. These three approaches are not isolated and can be used in one research simultaneously, just like Pitkänen analyzes the landscape meaning of the second-home in Finnish Lakeland [33].

With regard to the attributes of landscape, as Waterton notes, it is multi-faceted, such as multi-sensory rather than only visual, and coexists in materiality and emotion, more than textual, more than human, etc. [34]. Accordingly, we found that the representation and non-representational theory generates a rich theoretical resource for analyzing landscape changes. Representation is a textual process of creating meaning, which gradually complicates the meaning of things through the visual expression of language and various symbols. In other words, representation focuses on the meanings of a landscape constructed under the combined effects of historical, cultural, political, and other factors [35]. This is in line with the second cultural landscape analysis method, which explores the cultural significance, cultural change, power struggle, and identity of landscapes. As Daniels and 
Cosgrove point out, cultural landscape research pays attention to the changes in the form and function of landscape and the changes in the social relations and cultural meanings that lie behind them [36]. However, those daily experiences, habits, and emotions that are related to landscapes, complex temporal, and spatial attributes of the daily geography, and materialization and technologized daily life practices are often challenging to symbolize, leading to the observation of landscape changes by non-representational theory [33].

The non-representational theory was proposed by Thrift to respond to the 'mesmerized attention' given to texts and images that had occluded 'a lot of the little things' [37]. The non-representational theory calls our attention to the practices and emotions that are immediate, dynamic, and cannot be represented in daily life. It corresponds to the third landscape analysis method, the experiential approach, which regards a landscape as a way of being. These practices that cannot be symbolized are also rooted in the landscape's historical, social, cultural, and political background, with a deep geographical imprint [34]. Simultaneously, due to their randomness and subjectivity, they often can more acutely reflect the landscape's changes and meaning. However, it must be noted that the nonrepresentational theory should not be read as an endorsement of an approach that denies representation. Instead, both theories relate to the primary forms of cognition, coding, and production of social and cultural geographical knowledge, albeit focusing on different aspects of landscapes [38]. Therefore, the interpretation of landscapes needs to combine both approaches.

The waterway landscape that this paper focuses on is a specific type of spatial element, formed mainly by a waterway in the geographic environment. It is important to mention that whether a waterway landscape is cultural or not does not depend on its natural or artificial form, but rather on the cultural imprints on the land (water). In Section 4 of this paper, we will justify why the waterways in Hongcun Village can be regarded as a cultural landscape by revealing the cultural meanings and values behind it through representation. However, as Vallerani has noted, the water landscape is able to reflect the fluvial sensibilities towards the socio-natural world, as well as for the 'fluvial sense of place' in human-water relations [14]. There is a need to study the embodied and sensory, as well as the affective, experiences of waterways, the 'connections between body movement, and the formation of a well-grounded fluvial consciousness' $[14,39]$. Concerning the extraordinary variety of traditional social practices, memory, affection, and habits related to the silent presence of waterways, it is necessary to apply the non-representational theory to analyze the 'fluvial sense of place' to see what changes have been made over temporal and spatial variation, which will provide a nuanced investigation of various types of actions and movements occurring in the mobility era. As for the governance of the waterway, embracing the intangible dimensions of the waterway and adopting a new cultural approach that considers the links between ecosystems and human wellbeing and the cultural services provided by the ecosystem are also increasingly stressed [10,39]. This point offers insights for examining the management of Hongcun Village's waterways and the sustainability of the cultural landscape.

\section{Methodology}

When interpreting landscapes, qualitative methods help researchers approach, describe, and analyze their deep, complex meanings and sociality. Before the data collection, two pre-researches were conducted in Hongcun Village (hereinafter: Hongcun) on 30 October 2018 and 8 July 2019. The aim was, on the one hand, to listen to the tour guide's explanation of the scenic spots and inspect the actual situation of the waterways to establish a basic understanding of the area. On the other hand, from a practical perspective, the aim was to observe the changes of the waterway landscape and residents' reactions. The Wang family clan received particular attention because they are the founders of the waterway landscape in Hongcun.

After identifying the research objectives, that is to understand how the waterway landscapes are shaped, polluted, and managed in the process of tourism development, 
the data collection took place from 30 August to 1 September 2020, and from 11 to 14 November 2020. Non-participatory observations, semi-structured in-depth interviews, archival research, and secondary data, such as relevant policy texts and statistics, were applied in this study. We sought to uncover the personal and community's narratives which articulating the waterways to the rise and fall of Hongcun and the daily life of the community. Non-participatory observations ran through the entire fieldwork. As the waterways flow through the western, central, and eastern area of Hongcun, the authors lived in different homestays ran by the locals in different blocks and moved around every day to observe and record.

In-depth interviews were conducted by directly approaching villagers, introduction via local friends, and snowball sampling processes. In total, we conducted 35 interviews in Mandarin with local residents, government officials, tour guides, and migrant tourism entrepreneurs. The in-depth interviews lasted from $30 \mathrm{~min}$ to one hour. Some respondents were interviewed twice for clarification. Specifically, two descendants of the Wang family clan provided us with the village's history and local life through oral history. A total of 25 local residents directly related to the experience of the waterways were interviewed to understand their views on water pollution, the changes in the waterways, the people's daily habits, and the local culture. Then, 5 leaders of the village committee and town government were interviewed on the demographic changes in Hongcun, the operating status of homestays and restaurants, the source and status of water pollution, the treatment measures and their effects, and the existing difficulties. Tour guides and migrant tourism entrepreneurs' understanding on the waterway changes were used for auxiliary analysis. In addition, having established a trusting relationship with a few local residents, some details about Hongcun were verified by them though online social software.

With respect to the archives and textual data, choreography about Hongcun's waterways were systematically scrutinized, including the Water Patterns in Hongcun Village, Hongcun Village Choreography, Reading Huizhou, and Heavenly Huizhou, which aim to elaborate the historical process of the waterway landscape construction, and the structures and functions of waterways. This study also delved into the local policy documents, statistics, and related news reports to examine the extent to which policy discourses have been materialized in concrete programs of waterway pollution control. All the above data are integrated into the corresponding empirical section according to the research questions.

\section{The Historical Process of Waterway Landscape Construction in Hongcun and Its Cultural Meanings}

\subsection{Construction Process of the Waterways}

The construction process of Hongcun's waterways is inseparable from the construction history of the village. To better understand the structure, function, cultural significance, and the changes and management of the waterway landscapes in Hongcun below, we first outline how the construction of Hongcun is integrated with water from a historical perspective.

The ancestors of the Wang family clan have lived in Tangmo Village of the Huizhou region for a long time. Wang Renya, the 61st ancestor of the Wang family clan, ran a timber shop which suffered a fire, thus dissolving all of his assets. Feeling too ashamed to face his family and attracted by the nearby environment, he decided to move to the Qishu Village. As a temporary dwelling, however, Qishu Village is not the best location. Accordingly, he left the last word that the residential site of his descendants should be south of Leigang Mountain [40].

For the same reason of fire and war, the 66th ancestor, Wang Yanji, followed the ancestor's last words and moved to Leigang Mountain's hillside with his family from the Qishu Village in 1131. After his settlement, Wang Yanji purchased land, and it took him 22 years to build 13 buildings. The place was deemed to be the prototype of Hongcun. The name Hong in Chinese character means prosperity and flourishment. At that time, a Xixi River was traversing Hongcun from the north to the south. For Wang Yanji, it was a pity that the Xixi River could not meet the Yangzhan River to the west of the village. What 
was unexpected is that, on May 15 of the lunar calendar in 1276, a colossal flood broke out in Hongcun, which caused the Xixi River to be diverted. As a result, it turned the original Xixi River into a dry beach, which then developed into a large and empty place, thus creating suitable conditions for a base site for village construction. Thus, combined with the gradually increased population in Hongcun, villagers went down the mountain to build houses and settled down in the current location of Hongcun $[40,41]$.

With the Wang family clan's reproduction, when the 74th ancestor, Wang Xuanqing, was in charge of the clan affairs, he valued the geomantic omen. He invited geomancers to investigate Hongcun, hoping it would benefit the long-term development of the village. The geomancer pointed out that the spring water from the center of this village was essential. Ponds should be dug to store water to prevent fires. However, in a turbulent era, Wang Xuanqing was too old to carry out this project. Thus, he wrote down this viewpoint from the geomancer into the genealogy and passed it on to his descendants.

In 1403, after reading the genealogical records, Wang Siqi, the grandson of Wang Xuanqing, planned to build an ancestral hall not far from the village's spring water. At that time, people from the Huizhou region were firmly attached to the clan ideology. Events such as family members' wedding and funeral ceremonies, sacrifices to ancestors, punishments for evil, and praises of virtue, as well as discussing primary business, all needed an ancestral hall to host gatherings of the town people. Regarding the specific site selection, Wang Siqi hired the geomancer, He Keda, from Xiuning County to investigate Hongcun. He Keda believed that the last geomancer's plan was strictly correct, but it should be extended, recommending that a ditch be dug to bring the Xixi River water into the village. In short, this plan was to draw water into the village, dig the Yuezhao Pond, and build an ancestral hall [40-42].

Due to the political mission of going out as an official for 20 years, however, this series of projects was completed with Hu Zhong's assistance, who was the wife of Wang Siqi. Hu Zhong was the third daughter of Hu Lichao, a famous geomancer in Xidi Village. Since she was a child, she liked reading and had good talent, potentially due to her good education, which she received from her family. After marrying into Wang's family, she needed to take care of her own family, while leading her clansman to create the tribal foundation. According to the record of the "Grand View of Our Clan's Sages" (Chi: Wuzu Xianxian Daguan), Hu Zhong buried the ancestral tomb, built the ancestral hall, dug the Yuezhao Pond, made the waterwheel, and dug the Shuizhen Ditch. She also left her last wish to dig Nanhu Lake. Nevertheless, the construction of Nanhu Lake was not completed until 1610, when Wang Kuiguang with another 16 people were the most powerful in the family clan. At this point, the whole construction of the waterway landscape in Hongcun was completed [40-42].

\subsection{Structures and Functions of Waterways}

Hongcun's waterways are composed of six structures: Shi'e'tou Dam (Stone Dam), Shuizhen Ditch (Water Channel), Yuezhao Pond (Moon Pond), Water Garden, Nanlu Lake (South Lake), and Water Well, which together constitute an organic and interpenetrating waterway landscape (Figure $1 \&$ Table 1). With the elaborate design layout, the waterways function well in fire prevention, drinking and washing, irrigation, grinding rice and flour, environmental construction, and temperature regulation. The functions of the waterways satisfy the self-sufficient development state of the agricultural society in ancient China and are integrated with the regional culture of the Huizhou region (Table 2). 
Table 1. Six structures of waterways.

\section{Structures}

Shuizhen Ditch

Yuezhao Pond

Water Garden

Nanhu Lake

Water Well
Specific Description

It traverses the Xixi River water so that the upstream starts to store water and raise the water level, with a culvert to divert water into the village. A spillway is built at the turning of the waterways inlet $30 \mathrm{~m}$ to the south to lower the water level when a flood occurs.

It is divided into the major ditch and the minor ditch. The major ditch is subdivided into the upper ditch, the middle ditch, and the lower ditch. Stone platforms and hydrophilic stone steps are built to facilitate washing.

It is located in the center of Hongcun. Its water comes mainly from the minor ditch drawn from the Xixi River, with a small amount of spring water. It has one water inlet and two outlets.

It is the courtyard garden, which is built close to the waterways in Hongcun. By drawing water from the waterways, digging ponds, and setting up pavilions, various distinctive Water Gardens were built and created.

It is located at the end of the waterways. Its water inlet is located at the center of its north shore. It has five water outlets, one of which drains into Xixi River, and the other four drain into paddy for irrigation.

Hongcun once had more than eight old water wells, including both the public and private types. Their role is to avoid a situation in which the water in the Shuizhen Ditch is not drinkable when the Xixi River is flooded.
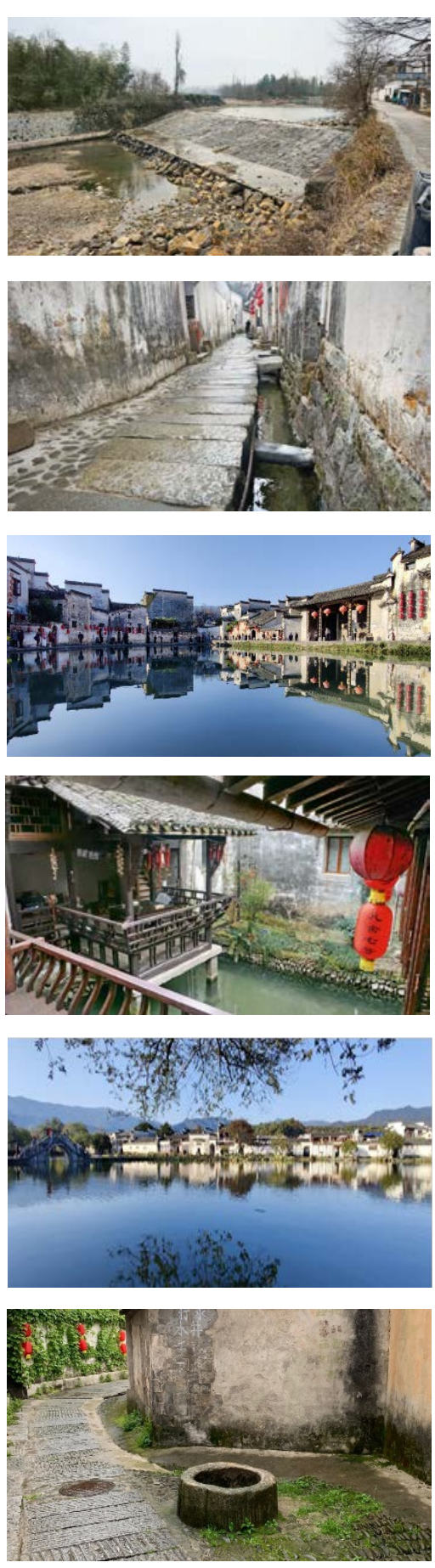
Table 2. The functions of waterways.

Functions of Waterways

Fire prevention

Drinking and washing

Irrigation

Grinding rice and flour

Environmental construction and temperature regulation
Specific Description

The ancestors of the Wang family were often trapped by fires. The houses, with their inner structure and decoration in wood, increase the fire risk in the whole village. Moreover, villages in the Huizhou region, including Hongcun, are habitually populated with houses built very close to each other. Once a fire breaks out, the whole village is damaged.

It aims to satisfy the basic needs of local life. Most residents are within $60 \mathrm{~m}$ from the waterways. Strict regulations for using water were set down by the Wang family clan. Before 8 a.m., water is only allowed for drinking and not allowed for washing. Violations will be punished by the patriarch.

Irrigation objects include flowers and plants, bonsai, vegetable fields, and paddy. Water from the Nanhu Lake occupies a central role in irrigation for farmland. There are four outlets of the Nanhu Lake that drain into the paddy located downstream of the lake, with an area of more than 6.67 hectares.

There is a section of the major ditch on the middle ditch with a relatively sizeable topographical drop. It is here that Mrs. Hu Zhong made use of the water drop to make waterwheels, facilitating villagers' grinding of rice and flour. When there was no electricity in the past, the waterwheel was like a grain-processing factory. The waterways running through the village can improve the microclimate, including improving temperature and humidity, purifying the air, and beautifying the environment. The waterways also provide aesthetic value, becoming a place for poets (including villagers) in the past to express their emotions.

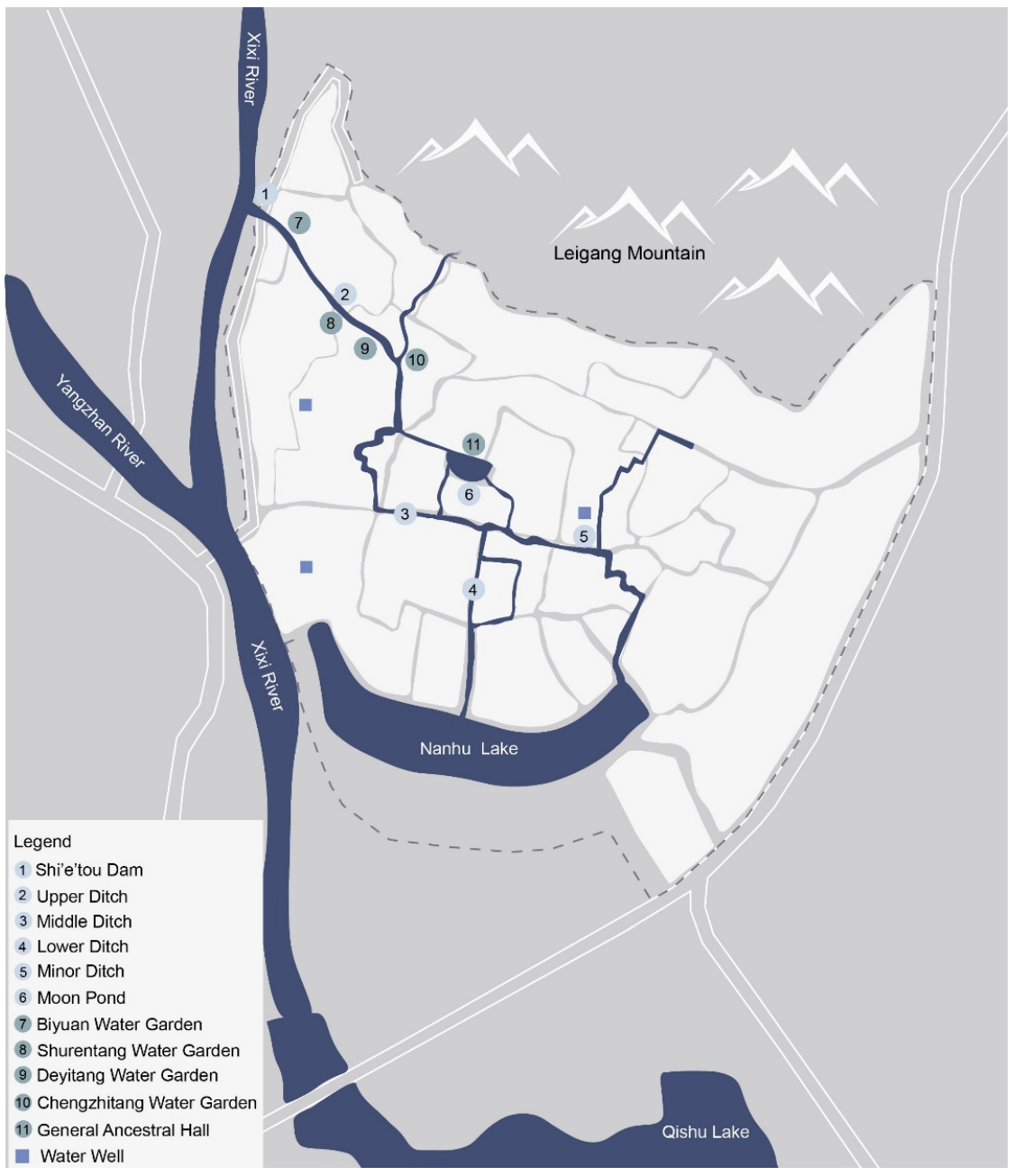

Figure 1. Waterways of Hongcun Village. Source: the authors. 


\subsection{Cultural Meanings of the Waterway Landscape}

A landscape refers to land shaped by humans, including the activities of inhabitants, how they build their homes, and how they belong to this land. More precisely, a landscape is a mark left by a group of people and a community product $[28,35]$. The waterway construction in Hongcun centralizes the wishes, ambitions, and gumptions of generations of clan villagers, showing the Wang family clan's grand plan for water management, shrewdness for water storage, and wisdom in terms of water drainage, which have resulted in an improved living environment. Thus, the waterways of Hongcun are more than a simple object; they carry meaning and agricultural wherewithal. Just as Daniels and Cosgrove argue, the landscape is not regarded as a material expression of a particular relationship between land and humans, but a way of seeing, a cultural image, a pictorial way of representing, structuring, or symbolizing surroundings [36]. In this sense, the cultural meaning behind the waterway landscape can be uncovered from its historical document as a text.

The waterways in Hongcun embody the philosophy of "harmony between man and nature" in Chinese traditional culture. It emphasizes that nature and human beings are regarded as a whole, requiring people to respect nature and care for the environment. Humans are considered products of nature and components of nature, whose relationship with nature is compatible, instead of antagonistic with nature. The waterways that draw water from the Xixi River run through Hongcun according to ingenious design and layout arrangements, which then satisfy the residents' daily needs [41,42]. After being used and circulated, the waterways finally flow back into the Xixi River and return to nature. The reverence for the indispensable water resources is reflected in the village's water protection actions, including regulations on washing schedules, the establishment of water conservation areas, etc. Furthermore, those elegant folk buildings built in the Ming and Qing Dynasties are closely integrated with nature to create a living environment that is both scientific and attractive. There is a dialectical unity between people and the environmentmountains are green, trees are vivifying, land lends glory, and the village is full of vitality. All of these things are influenced by the waterways. Therefore, it can be said that the waterways in Hongcun reflect the pursuit of internal unity and harmony between humans and nature $[41,42]$.

The waterways in Hongcun symbolize the specific traditional regional culture of the Huizhou area. First of all, Confucian etiquette and clan ideology are thoroughly manifested in the process of its construction. Neo-Confucianism, which originated in the Huizhou region, further civilized the rural areas and formulated strict clan rules for governing the rural societies [40]. Thus, affairs pertaining to the waterways in Hongcun must be managed by the patriarch, instead of a casual person. The hierarchy, authority, and status of the patriarch cannot be questioned or challenged. Only by encountering a patriarch with a strong ability and long-term vision can the project, which has lasted more than 200 years, be continued. People's daily water use is also restricted by clan authority. In the feudal era, Mrs. Hu Zhong left two admonishment pieces, which have become classic quotations for generations, regarding the protection of water resources in Hongcun. It is evident that the clan is the main undertaker of rural social governance. In addition, the construction of the waterways is regarded as a critical event related to the rise and fall of the Wang family clan. This is naturally included in the genealogy, which records the reproduction of the family and achievements of essential people. After several generations of hard work, a strong family cohesion and inherited family responsibility have been maintained in relation to the waterways $[42,43]$.

Secondly, the geomancy theory is deeply rooted in the guidelines for the construction of the waterways. From the Huizhou people's philosophy, the mountain is seen as the foundation and the water is seen as the lifeblood for their life. After determining the village's spatial pattern, they would emphasize the conditioning and utilization of the water, especially in relation to the construction of the waterways for the whole village. People believe that the reasonable construction of the waterways and the favorable physical 
environment will directly influence their clansman's prospects and the whole village's development. During the waterways construction process, projects such as the water diversion into the village, the digging of Yuezhao Pond, and the excavation of the Nanhu Lake, were all investigated by geomancers hired by the Wang family many times [40]. The aim of this was to avoid disasters, satisfy fortunes, and lay a solid foundation for the future development of Hongcun [43].

Finally, the temperament of Huizhou merchants is engraved in the morphology of waterways. The Huizhou merchant group was one of the most distinctive top ten regional merchant groups during the Ming and Qing Dynasties in China. They spare no effort in advocating the idea of the righteousness of profit, strictly sticking to business guidelines, making efforts to be benevolent lovers, and realizing the value of life with the money they earn. Huizhou merchants are particularly enthusiastic about social welfare and charity and full of social responsibility [41]. Wang Shengping, a native of Hongcun, was a distinguished merchant who had been doing business outside Hongcun. Hearing that Wang Siqi and Hu Zhong, a couple, were planning to draw water into the village, Wang Shengping immediately led his family to move back to Hongcun and successively donated more than 12,000 taels of silver to fund the projects of the Shuizhen Ditch, Yuezhao Pond, and General Ancestral Hall [40]. Simultaneously, he acted as the supervisor for these projects, handled the scheduling, and made a significant contribution to the construction of Hongcun [40].

\section{The Impact of Tourism and Water Pollution on the Waterway Landscape}

\subsection{Tourism Development in Hongcun and the Causes of Water Pollution}

Historically, Hongcun has always been an agricultural hamlet. After the tourism development in 1986, the industrial structure of Hongcun was rapidly modified, turning tourism into a pillar industry. In 2000, together with Xidi Village, Hongcun was added to the World Heritage List by UNESCO, commenting that "the two traditional ancient villages of Xidi and Hongcun still largely retain the appearance of those villages that have disappeared or changed in the last century. The style of its streets, ancient buildings, decorations, and folk houses, with complete water supply systems, are all unique cultural relics". Additionally, Hongcun also won the great honor of the National Key Cultural Relics Protection Unit (2001), the First Group of Chinese Historical and Cultural Villages (2003), and the " $5 \mathrm{~A}$ " level Tourist Scenic Spot (2011). After receiving these awards, Hongcun began to attract numerous tourists, which is supported by statistical records. In 1998, 39,400 tourists visited Hongcun, accumulating a direct ticket income of 482,300 yuan. By 2018, 20 years later, the total number of visitors reached 2.3 million, and the ticket income reached 138.12 million yuan, which is 58.4 times and 286.4 times the 1998 levels, respectively. However, the excess tourism on the demand side and growing tourism business on the supply side sharply affected the waterways environment, causing pollution.

The sources of tourism-related water pollution mainly include three aspects: many villagers and migrants who ran homestays, restaurants, and leisure teahouses in Hongcun drained the sewage directly into the waterways due to the lack of a proper sewage system before 2016; the increasing number of students from art schools across the country, who come to Hongcun for sketching and artistic creation, leave drawing garbage in the waterways [44]; and the phenomenon of uncivilized tourist behavior affects the water environment of Hongcun. Besides, there are another three aspects that need to be taken into consideration to gain a more comprehensive understanding of the causes of water pollution in Hongcun (Table 3). 
Table 3. The causes of water pollution in Hongcun.

$\begin{array}{r}\text { Causes of Water Pollution } \\ \hline\end{array}$
lack of a proper sewage system

Pigment sewage from sketches; inadequate supervision

Uncivilized tourist behavior

Sewage from the upper Xixi River; increasing pollutant emissions originated from the modernization of life; insufficient environmental protection awareness of the villagers
There are 520 households in Hongcun. The number of accommodation facilities and restaurants in Hongcun has reached 350 households, of which 65 are related to catering, and the rest are accommodation (Statistics for 2020). During the peak tourist periods, the daily reception volume in Hongcun reaches more than 20,000 people.

Art creator stay longer in Hongcun and consume many drawing boards, drawing paper, and oil paints. Sometimes pigment water is poured and brushes are washed in the waterways, containing a lot of heavy metals.

Some tourists of a low moral character throw rubbish directly into the water; some tourists spit straight into the ditch; some parents even allow their children to urinate or excrete directly into the waterways.

More than 1000 people live in the villages on the upper of the Xixi River; 1482 people live in Hongcun (Statistics for 2018), and the residential population of Hongcun has been stable in recent years due to the control.

\section{Illustrating Picture}
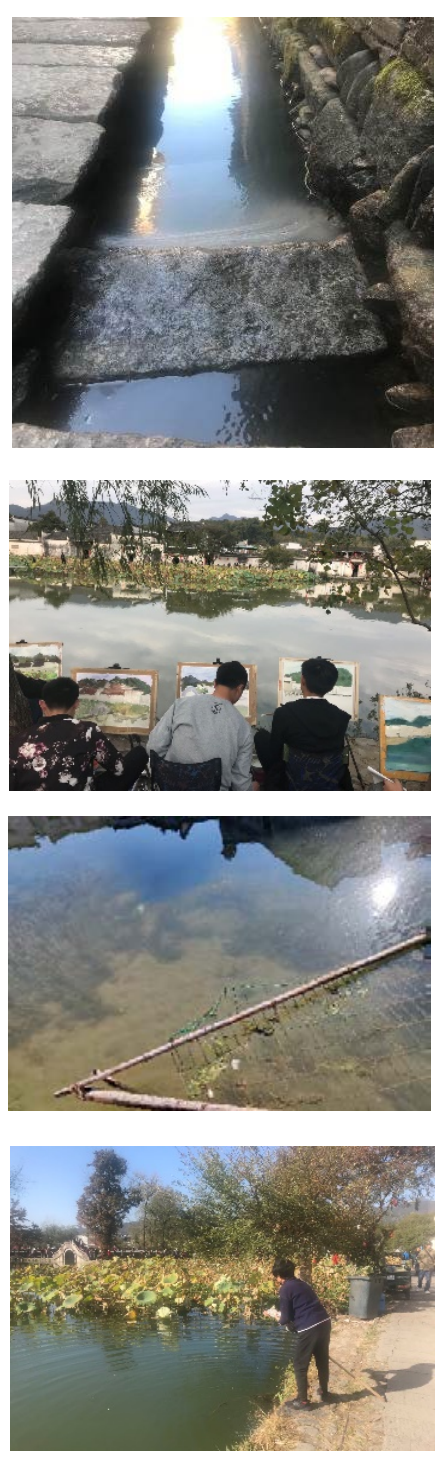

Note: The source of the pictures comes from the authors.

\subsection{Changes in the Waterway Landscape}

There is no doubt that Hongcun's disordered and unrestricted tourism development in the early stages exceeded its social and environmental carrying capacity. People joked that the so-called "cow-shaped village" in Hongcun was slowly suffering from "chronic gastroenteritis." Simultaneously, tourism has caused significant changes in terms of the land use, population structure, and traditional defense facilities. For example, the tourism-based land use increased by almost four times to 262.9 hectares from 2003 to 2012 [21]. Migrant business households account for about $40 \%$ of the total population in Hongcun. With the influx of immigrants, tourism business owners, and tourists, as well as the external migration of local residents, the clan consciousness and family notion initially tied to Hongcun were further diluted, and the waterways no longer serve as a family bond. All these have brought influences and changes to the waterway landscape, previously valued by the villagers. This can be captured by the non-representational geographers, who define the landscape as a process and an assemblage of the embodied, practiced, and experienced elements of life [45]. 
The most direct manifestation of this is that residents no longer drink water from the waterways. When asking about the waterways' purity in the past, their memories well up out of the depths of the unconscious [46], and they express dissatisfaction with the status quo in recalling their previous water-use practices. A 50-year-old local woman who ran a homestay told us that "the water was spotless and safe before the tourism development. At that time, we always took a wooden bucket to get water from the ditch for a drink before 8 a.m. After the tourism development, many local people opened inns, and they directly discharged sewage to the ditch. After that, nobody dares to drink again". Another 45-year-old local woman who ran a restaurant also said that "the water in Hongcun could be drunk 20 years ago, but now there are too many tourists, and the groundwater is seriously polluted. We used to have pressure wells, but now they are all abandoned. As the pressurized water is not clean, a lot of oil pollution floats up." The landscape itself can be incorporated into the habitual process [45]. From today's daily life and daily procedural practices, residents' habit of using water has changed over time, and the meaning of the waterway landscape, as reflected by specific residential patterns, has started to become disorganized.

Secondly, the waterways' washing practices are not based on the order and aesthetic perception of daily washing anymore. The specific rhythm of washing has been disrupted and is now characterized by randomness. Regarding touch, as the dirt in the waterways can be seen, a certain physical and psychological distance is maintained from the water [34]. From our fieldwork, only some older residents still keep this traditional lifestyle, as they insist on living in a thrifty way, avoiding paying water utility bills associated with using tap water and washing machines. In consideration of their health, however, young people rarely use waterways to do their washing. Most of the washing activities are conducted in the morning, as the severe sewage from the inns and restaurants in the afternoon prevent them from washing. Even though washing clothes and vegetables as a daily folk landscape can still be seen in the upper ditch and middle ditch, we were told that, after washing dishes and clothes in the waterways, villagers would clean them once again with tap water at home for safety. Those who live near the lower ditch would not wash due to the severe pollution accumulation. Without the supervision and discipline of washing activities and awe for water, the local people wash mops and shoes directly in the waterways.

Thirdly, the fire protection function of the waterways has been weakened. To a certain extent, fire shapes the Huizhou region's unique architectural forms, including the high wall, broad street, narrow lane, and the unexposed wooden structure. Nevertheless, nowadays, the experience of collecting water to extinguish fires almost no longer happens by relying on living utensils, such as buckets, basins, and water vats by the family clan. Due to the tourism development and the world's cultural heritage protection regulation requirements, modern fire protection technology has become dominant and covered the whole village, although without changing its wooden structure and original style. There is a rigid requirement that inns must install fire hydrants and fire extinguishers, and restaurants must install fire doors. The Hongcun Committee director pointed out that there is now a firefighting center equipped with a fire lane that has a network system in the village. Once a fire occurs, the alarm will automatically be sounded, and a small fire truck will quickly arrive at the fire scene. Villagers told us that a fire broke out three years ago in Tiandeng Shitang, a restaurant in Hongcun. The fire was extinguished by fire trucks, and the fire prevention effect of the water was minimal.

Fourthly, the irrigation function of the waterways has been lost. For tourism development purposes, the land around the Hongcun Scenic Area needs to serve the construction of tourism infrastructure. As a result, the land use in the traditional period has undergone earth-shaking changes. For example, on top of a former farmland, a parking lot, the entrance and exit of a scenic spot, a ticket office, a tourist toilet, a lotus landscape pool, a grove, an electric vehicle charging station, and a handicraft commodity market were built in the south of Hongcun, as well as the No.476 provincial highway and the Dongshanxia parking lot, with a total area of about 8 hectares. Traditionally, the residents' farmland work 
resonates with the waterways' irrigation function, showing dynamic and interdependent body-landscape relations and building a homeland through practical application [45]. Due to the demand for tourism land construction, however, agricultural land has been transformed into urban construction land, and the irrigation function of the waterways has withdrawn from what it was previously. This also means the fading of the doings, practices, and performances of the people in the rural areas and the disappearance of rural spaces and places that once formed a significant part of people's everyday lives [47].

The environmental construction of the waterways is the only function that still plays its role, albeit silently. The waterways are flowing, and the amount of water remains relatively stable. As shown in the data, the flow velocity in the Shuizhen Ditch is $21.6 \mathrm{~m} / \mathrm{min}$, and the flow rate is $7.95 \mathrm{~m}^{3} / \mathrm{min}$; the water depth in the Yuezhao Pond is $1.2 \mathrm{~m}$, and the water capacity is $1500 \mathrm{~m}^{3}$; and the water depth in Nanhu Lake is $0.8-1.1 \mathrm{~m}$, and the water area is $20,247 \mathrm{~m}^{3}$. Thus, the waterways still benefit Hongcun in terms of regulating the temperature, humidity, and local microclimate. However, something has been subtly transformed in the affective memories towards of the environment $[45,48]$. Compared to the ancient people (including the locals), who praised the rural artistic conception of the Yuezhao Pond and Nanhu Lake and recorded the customs and folk activities of Hongcun in their poems, this tradition has gradually faded away and been replaced by the increasing use of a lens by tourists to record their personal travel experiences or by professional photographers to capture the natural beauty of Hongcun. Informants complain that local people seldom care about the cultural presentation. More villagers regard Hongcun as a profitable business instead. They are mostly concerned with how much money can be made by receiving tourists today and what the source of tourism will be tomorrow. Informants then express helplessness that everyone is in a state of financial insecurity and life pressures. For this reason, they go into the business field, rather than promoting their local culture and family education. The latter, however, is exactly the splendid side of the Huizhou regional culture. The local elderly people sigh with sadness when they think about how they can reshape the cultural cornerstone in the mind of the young people and find their spiritual home, which has been taken from them.

Overall, the aforementioned waterway landscape changes coincide with the villagers' opinion that the current waterways in Hongcun are just a landscape for everyone to visit, while its meaning and connotations, compared with the past, have changed. That is to say, combined with the analysis of the everyday life and everyday practices that constitute the spaces and places in which life "takes shape" [47], the people in Hongcun have gradually moved away from the traditional function and meaning of the waterways. In a cultural sense, the waterways' pollution marks an abandonment of the ancient philosophy of harmony between man and nature. To a large extent, the tourism development has changed the landscape meanings rooted in the lived history and the experience of those meanings, thus bringing about the loss of a way of life and an essential part of the identity of Hongcun and threatening its waterway landscape and aesthetics [12].

\section{Waterways Pollution Control and Sustainable Development in Hongcun}

Hongcun's destiny is closely intertwined with water. Confronting the dilemma caused by water contamination and tourism development, both the local government and native residents must promote the resilience of the social-ecological system of Hongcun under external disturbances, as sustainable tourism development can only be achieved in a sufficiently resilient social-ecological system $[49,50]$. Here, the sustainable development concept follows the resource-based tradition, which reflects the limits of the original conditions of the resources used in tourism, highlighting the need to protect the natural and socio-cultural environment from unacceptable changes caused by tourism activities [51]. Below, we link sustainable outcomes to the resilience-thinking framework and elaborate the strategies for waterways pollution control. 


\subsection{Pollution Control for Homestays and Restaurants}

The ecological restoration was carried out at the outset. From March to early May of 2016, more than 400,000 yuan was invested by Yixian County to restore the Yuezhao Pond. The construction manager indicated that the first stage of the work included draining the Yuezhao Pond completely, removing the rancid silt, and applying a biological ameliorant to eliminate internal and non-point source pollution. Then, more than 100,000 submerged plants with the capacity to regenerate the waterways were planted to absorb the nitrogen and phosphorus organic matter in water. In the later stage, the submerged vegetation in the Yuezhao Pond was harvested regularly to reduce the nitrogen and phosphorus pollution in the water body. In the South Lake, water hyacinth and myriophyllum that are able to beautify the environment and purify the water quality were also planted in small areas. The director of the village committee told us that, to some extent, this kind of pollution control method has indeed suppressed the occurrence of hypoxia and eutrophication in the water body. However, its effect will not be enduring. Oil pollution floating on the Yuezhao Pond's surface and the Nanhu Lake can still be observed.

Another approach to pollution control is the installation of sewage filtration equipment and the implementation of a sewage collection project. In July 2016, the Hongcun Town Government issued a document emphasizing the need to control the disordered discharge of oily sewage from the source. All villagers and business households are required to prohibit the direct discharge of sewage into waterways, and filter tanks must be installed and constructed simultaneously. To implement this work, the government established a Comprehensive Tourism Law Enforcement Team in July and August 2016 to supervise the project. A list of 31 households was confirmed through open and unannounced visits, and three months of limited sewage rectification was required from July to October. As a government-funded environmental protection project, the operator's sewage treatment equipment was installed for free, while those households that did not meet the standard faced business suspension for rectification. To a large extent, this project caused the sewage produced in Hongcun to be treated and then discharged, thus significantly alleviating the pollution, instead of directly discharging, like in the past.

At present, the projects of rainwater and sewage diversion and domestic sewage collection were implemented on the eastern side of Hongcun and won funding from the superior environmental protection department. This has allowed the projects to further expand their sewage collection and treatment range. However, these projects do not cover the entire village area. The point here is that the central and western parts of Hongcun are densely distributed areas, with ancient dwellings, narrow roads, and numerous alleys. The houses built in historical periods have no subgrade, that is, there is no soil or rock mass under the building that supports the foundation. While the domestic sewage collection pipeline needs to be buried underground, thus limiting the construction project. As the village committee director put it, "if the project is not carefully constructed, it will destroy the world cultural heritage, and no one can bear this responsibility." Many companies, therefore, are unwilling to take over this project at the risk of destroying the world cultural heritage. Simultaneously, the current sewage pipe standards and sewage treatment technology are centered on the urban context. They do not meet the requirements of the specific environment in traditional villages. The central government is also currently considering this issue. In the future, a set of plans and standards for ancient villages on sewage treatment will be formulated across the country. Consequently, Hongcun is still facing the dilemma of protection and development, including poor sewage infrastructure and local residents' strong desire for development, but it is impossible to restrict their livelihood and affect the city's macroeconomic operation.

The community response process for change is not only through top-down collective action, but also through the responses of households, individuals, and groups, enacting self-organized and positive collective action for community survival and well-being [52]. Daily salvaging of garbage and annual manual dredging are also in progress and have become routine work. Every morning, the cleaners clean up the moss and algae attached 
to the ditches' sides to make them run away without silting. In the Yuezhao Pond and Nanhu Lake, some cleaners specialize in salvaging garbage or pollutants in the water. The annual dredging work is usually conducted in December or January and organized by the village committee, with hundreds of people participating every year. Specifically, the dredging work in the waterways is divided into 14 sections. The most polluted section is about $150 \mathrm{~m}$ long and is where the party members and villager representatives to play their pioneering roles. The remaining workers are assigned a section on the basis of a lottery, and the sections are divided into 13 segments for 13 groups.

\subsection{Pollution Control for Sketch Pigment Sewage}

Political leadership is crucial in the legitimization of thorough resilience strategies [53], which is apparent in the remediation plan of sketch pigment sewage. For the local government, there is an urgent need to speed up the development of other scenic areas neighboring Hongcun, such as Pingshan Village, to which artistic sketching students could be gradually diverted to alleviate the pressure on environmental protection. In terms of managing of the scenic spot itself, the town government firstly holds special meetings for the Hongcun Sketching Base's business households and signs the letter of commitment and responsibility. Secondly, the sketching base owners and teachers are required to train students to regulate pigment sewage pouring, thus improving students' awareness of environmental protection. Thirdly, the town government, village committee, and tourism company arrange full-time personnel to conduct regular inspections. Once the harmful behavior of randomly dumping pigment and sewage is identified, it will be stopped. Those who caused pollution shall be punished by law enforcement team members. Simultaneously, both the colleges where the teachers and students are located and the business households of the sketching base would be notified and criticized.

A more practical approach was implemented in Hongcun, although the results are not very satisfactory and have failed to solve the fundamental problem. The town government adds a total of 20 pigment buckets in the scenic area, rationally distributing the sketching area and re-planning the placement of pigment collection buckets, which ensures that all pigment wastewater is poured properly. Then, four full-time cleaners are arranged to clean and transport the pigment sewage regularly. Moreover, they cooperate with the Environmental Protection Bureau of Yixian County to monitor water quality indicators monthly. However, follow-up investigations showed that after the sanitation workers transported the pigment wastewater outside the village, they directly dumped it onto unused land. Therefore, such a treatment method simply transfers the pollution source from Hongcun to the outside, without properly solving the pollution.

In addition to the targeted work mentioned above, the resilience of the waterways is also tied to the environmental governance in a broader context, thereby connecting with other key regional resilience strategies, including the classification of domestic waste and construction waste and the river chief system [53]. To regulate villagers' daily behavior, it is a requirement that domestic garbage should be put in the Hongcun domestic garbage transfer station in a unified manner, and construction waste must be cleared and transported to the garbage site as landfill. The river chief system is a political institution with Chinese characteristics to protect rivers and control river pollution. In the political division of labor, the town mayor serves as the river chief, the director of the village committee serves as the executive river chief, and the village group leader, who supervises the river, is the river patrol. By inspections, the river's current status and pollution sources under their jurisdiction are noted and detected comprehensively, so that rectification plans and rectification measures can be implemented in time.

Observing community resilience in action aids in understanding what community resilience is and how it occurs [50]. In this case study, the local governments play their agency in the environmental governance of the waterways, which matches China's political characteristics of a "strong government and weak society." Community participation is mobilized through institutional arrangements, such as policy restrictions, sewage systems 
construction, ecological restoration, routine maintenance, etc. This dimension of destination resilience challenges apolitical notions of resilience found in the literature [53]. To a large extent, water environment deterioration is curbed, and the physical appearance of the waterway landscape is maintained. What kinds of social relationships and processes resilience come into action [50], however, are still needed to be thought further, as discussed in the following section.

\section{Discussion and Policy Implication}

The call for transcending the tangible and static aspects to protect the cultural landscape and underlining the protection of living culture is increasingly vital. Non-represen tational theory is interested in everyday life, and the everyday practices that constitute the spaces and places in which life takes shape, which is highly consistent with that call [34]. Non-representational work on landscape defines landscape as practice, materialities and sensibilities with which we see, and has shown how landscape may be thought of as a process which potentially 'animates' the embodied subject [45]. For the waterway landscapes of Hongcun, physical control and management by the local governments are not comprehensive, nor do they achieve social and cultural resilience. In the following, we combine non-representational thinking with resilience to examine the current problems of the waterway landscapes of Hongcun in the development of tourism, and discuss and suggest how the way different actors encounter and interact with the environment and daily practice may guide landscape changes into sustainable pathways and better represent the rich cultural meanings of waterway landscapes.

Our formal fieldwork was conducted after the COVID-19 pandemic. When asked about the apparent changes in Hongcun before and after the epidemic, many informants claim that the waterways were much cleaner than before due to fewer tourists. There were no floating objects or oil on the water, and many birds and other animals also came back, which was precisely the ecological scenario of this village 20 years ago. COVID-19 is like an unrepeatable social experiment, from which we can see the vast impact of tourism development on Hongcun's water environment. Water pollution caused by tourism is a leading factor affecting the waterway landscape changes, which is the central argument of this paper. Faced with the same (ecological) pressures by tourism, locals in Hongcun are eager for tourists so as to increase their income, which is in stark contrast to previous observations in Venice and Barcelona by Cristiano and Seraphin, where residents boycott the overtourism development $[25,54]$. Hence, it appears that it is too early to emphasize the concept of overtourism in Hongcun. The non-human dimension of the waterway landscape, however, needs to be emphasized for the purpose of environmental healing in tourism. As Crossley argues, the wildlife is an intrinsic dimension of the landscape, forming a motif of environmental hope that symbolizes life, regeneration, and resilience [22]. Similarly, Cheer suggests moving "beyond viewing people as external drivers of ecosystem dynamics and rather looks at how we are part of and interact with the biosphere" [55]. Both Crossley and Cheer's viewpoints echo the emerging trend of discussing issues of biodiversity conservation in humanized landscapes [56]. Therefore, reasonable control of the number of tourists rather than allowing an unlimited reception, restoration of wildlife habitats, and guaranteeing the tourism industry within the allowable range of the local carrying capacity, are worthy of serious consideration. In this case, people have more chances to place themselves into the encounter and interplay of affective intensities between everyday life and the non-human forces of nature [34], and the cultural landscape of the waterways of Hongcun would show a more authentic appearance, instead of a scene eroded by pollution, thus presenting the connotation of harmony and unity between man and nature [23], which Hongcun should have.

While the local government occupies a central role in nurturing tourism resilience in Hongcun, more can be done at the community level. For instance, the social responsibility of the host and the agency of the individuals need to be stimulated by enhancing their cognitive capabilities in areas such as environmental protection, compassion, and public 
duty. Some local operators told us that they really wanted to expose the bad manners of people who litter the waterways in their social chat group, so that these managers could remind their customers not to litter. However, after consideration, they did not dare to do it and only made compromises, silently giving way in order to make money. There is a sharp contrast between this mentality of the excessive pursuit of profit and Huizhou merchants' historical values. As mentioned in Sections 4.2 and 4.3, the waterways protection in Hongcun during the historical period benefited from a set of shared norms, values, and understandings derived from the inside of the village per se, including the trust, solidarity, social cohesion, expectations, identities, obligations and even sanctions. For Prager and Musavengane, these elements constitute strong social capital, which has the capacity to manage cultural landscapes for resilience $[57,58]$. Only when the locals care for the heritage from the inside can they work together to form a joint force in water pollution treatment. As Sheppard has added, a set of individual-based resilience-enhancing factors would also help the community to absorb the disturbances and change and reorganize their community more proactively [52]. More importantly, by institutional arrangement, converting the resilience-enhancing factors into contextual and conscious behaviors to protect waterways is an integral part of cultural landscapes.

Driven by profits, the demographics of Hongcun have changed dramatically. Although some local residents occupy favorable resources and locations in tourism, they are restricted by their economic conditions and operation ability as they have been in poverty for a long time, which hinders the improvement of the amenity of the buildings used for the reception and the quality of the tourist services. Hence, they are forced to rent or sell their house to outsiders to get money. Otherwise, it will be harder to improve their living conditions. On the other hand, the stronger operation ability of the immigrant operators has further squeezed the local businesses. This, in turn, has accelerated the exchange of populations. At present, the ratio of local people and non-native population in Hongcun has reached 5:5. The displacement by tourism gentrification has weakened or even dissolved the traditions, habits, daily life, and sense of place of local community. To pay the high rents, immigrant operators need to strive for profits to survive, which forces them to concentrate on their own business and ignore the protection of the waterways. For the resilience of cultural landscapes, it is necessary to cultivate the localization of the living habits of the migrants, especially the daily life related to the waterways, giving meaning to performance and practice [26]. For example, participation in, or even accountability for, the annual dredging work is encouraged. As Head underlines, putting culture into the landscape is particularly necessary in settler societies [56]. By integrating outsiders into a place-based wider network, community resilience is easier to be achieved, which also contribute to implementing new elements into the structures of cultural landscape [57,58].

As a village with great cultural heritage and traditions, Hongcun's physical pattern, including traditional architecture and waterway structures, has been well preserved. However, the inheritance of the culture, including the local culture and the traditional lifestyle, which are closely related to the indigenous community, is still neglected and underestimated. In the broader context of accelerating urbanization in rural China, a growing number of local people in Hongcun have separated from the rural context and have moved towards modern life. Therefore, in any case, the changes in the functions of the waterways are an inevitable consequence of social development, while the tourism industry has only accelerated the pace of these changes. As Plieninger points out, it would be as naive as it would be misleading to simply try to impede all forms of cultural landscape change. The challenge is how to address the changing character of landscapes, both in scientific and political terms [59]. In Hongcun, when confronting waterways pollution, strict measures, such as pollution source control, sewage discharge reduction, and living behavior guidelines for tourists and villagers have been adopted, which are indeed useful and rewarding. However, there is still a lack of flexible governance, and arbitrary decision occupies a large part. For example, restaurants run by locals are not allowed to wash vegetables in the waterways, and the government and tourism companies fail to cultivate and create a lively 
scene where the local community and waterways interact closely. From the perspective of the cultural landscape, the waterscape of Hongcun not only depends on whether the structure of the original waterway is complete, or whether the water is still flowing and at an adequate level, but also on how the landscape is animated [45]. More directly, Head suggests 'putting back in' people who were rendered invisible when conceptualizing cultural landscapes and resilience thinking [56]. In this case, the non-representational theory can contribute to the cultural landscape construction on the traditions, habits, and life stories associated with the waterways which have not been represented in the process of tourismification in Hongcun.

Fortunately, the fieldwork shows that the community has not become completely alienated from its waterways. Some informants insist that flowing water does not rot in Hongcun due to the exchanges of water and unenclosed drainage system. Thus, the water is still clean and can be used for daily washing. Besides, the daily use of the waterways by the local people is closely associated with their farmer identity, and the people claim that, unlike office workers, the mud on their clothes from doing farm work requires washing by hand, rather than in a washing machine. This shows that the locals still need to have daily interaction with the waterways, converting ordinary people's daily activities and behaviors in the context of the waterways into aesthetically esteemed sceneries, and preserving this kind of individuality of the place may become a great opportunity for tourism in Hongcun [5]. To use Vallerani's terms, it is this hydrophilia that constitutes the habits and traditional lifestyle of the community and maintains its authenticity [14].

In summary, in contrast to the literature review that expounds the waterway landscapes from representation to non-representational theory, this section follows a process of reflection on cultural landscape management from a reverse thinking. Non-representational theory ultimately goes back to representation by revealing cultures that do not yet have clear signs $[34,35,47]$, and assists to provide some guidance in the making of landscapes, which corresponds to how to build resilience in the cultural landscape. Indeed, the tourismification of Hongcun has driven the developer to select landscape symbolism that can be easily coded. That is, those elements that can be visualized, textualized, and symbolized are selected for place marketing. However, it is also easy to ignore the embodied and contextual aspects of the impacts of tourism development on the changes of waterway landscape. The biodiversity and non-human dimension that once symbolized the unity between man and nature; the responsibility and mission of indigenous community for the waterway conservation; and the 'fluvial sense of place' in human-water relations all used to be the performance of how human cultures interact with waterways and shape them into cultural landscapes. Suitable management strategies from the non-representational theory angle may help to direct the vanishing of landscape structures into creative pathways and reveal ways how functions fulfilled by traditional elements may be implemented into novel structures [59].

\section{Conclusions}

The development of all human societies involves complex interactions with water. The waterway landscape in Hongcun was created through several generations of the Wang family clan, the influence behind which is the traditional Chinese philosophy of harmony between man and nature and the specific traditional regional culture of the Huizhou region. In the wake of China's tourism development, this heritage, with rich historical and cultural meanings in architecture, geomantic omen, clan, and ancient village layout, is represented by the developers and their media, which has quickly become the object of tourist' gaze. However, the subsequent water pollution and changes in the demographic structure and land use have also altered the traditional functions and cultural significance of the waterways. These changes can be captured by non-representational theory, including local residents' memory, emotion, sensory experience, habit, and frequency of using water, and waterway-related agricultural practice. The present-day relationship among members of the society and their landscape is different from the socio-spatial relations activated by 
the waterways in the past. The waterway landscape of Hongcun nowadays functions as a tourist attraction, rather than serving traditional livelihood purposes. Without considering environmental sustainability, those activities carried out merely for economic benefits in tourism development decrease the value of the landscape [60]. Facing an increasingly serious water pollution issue, the local governments have taken various measures to control the sewage from homestays and restaurants and pigment sewage from sketches to enhance the stability of the social ecosystem, playing a crucial role in resilience strategies. However, not enough has been done to make actors' mundane embodied actions and their material world matter in tourism development schemes and landscape making [26]. In terms of sustainable tourism development, there also exists a dilemma of negotiation among the underground construction of a sewage treatment project, heritage protection regulations, and the strong local desire for tourism development, which remains quite a daunting task that has needed to be resolved for a long time.

In the words of Pitt, waterways have shared elements, but each is a unique landscape, and greater attention to all types of waterscapes is needed [11]. Our study thereby contributes to the existing waterway/cultural landscapes literature in the following ways. First, our study helps to understand the water utilization pattern of a profitable coexistence with a specific environment in the Huizhou region in the agricultural society of ancient China, where the hydrosphere prevails beyond Western Europe. In their work, Kaaristo, Pitt, and Owens conclude the research framework of Western inland waterway landscapes mainly describes waterways in the context of industrial society, as material manifestations of the nation-state that underpin processes of urbanization and modernization, as well as their representations $[10,11,39]$. Our study reveals the mode of coexistence between man and nature in ancient Chinese agricultural society and the philosophical and cultural views behind it, as well as the impact of tourism on waterway landscapes. This account is not based on industrialization, and it captures such subtle changes through non-representational theory and further responds to Vallerani's call for 'fluvial sense of place' in human-water relations [14], adding to a new narrative to the inland waterway landscape research that requires diversification.

Second, our study strengthens the connection between cultural landscape and resilience. To use Plieninger's terms, the potentials of integrating the existing knowledge on cultural landscapes and resilience remain vastly under-explored [59]. As a cultural landscape, our analysis regards the waterway landscape as the critical position of the social-ecological system of Hongcun. When analyzing the natural and cultural dimensions of waterways and the impact of tourism on waterway landscapes, water is put in the first place. Similarly, when discussing how to manage and protect the waterways from a holistic perspective, how water's role can enhance the resilience and adaptability of the waterway landscape is also reconsidered. In other words, this paper further emphasizes the potential of using waterways as a lens for studying social relations and the interactions between humans and the environment [11].

Third, our study offers a novel guiding framework and a way of thinking for analyzing and managing cultural landscape. Based on an overall collaborative thinking framework of representation and non-representational theory, the combined view through the lenses of cultural landscapes and resilience can put forward a deeper understanding of the causes, processes, and consequences of waterway landscape change as well as targeted management strategies [59]. We argue that this framing could be useful in other studies of cultural landscape, particularly when cultural landscapes are appropriated into tourism development and interfered with by external forces, and that it is needed to consider how to maintain its function, structure, and feedback without qualitative change.

This study also has some limitations. Methodologically, non-representational theory stresses immersive research, such as deep ethnography, which allows for access to diverse data with an open mind and an ability to restore the real world as much as possible. The lack of solid and in-depth ethnography in this paper, to a certain extent, limits the nuanced examination of the spatial and local multiple textures of the waterways in Hongcun. Future 
research could focus more explicitly on the importance of the quotidian and material aspects of waterway life in relation to the cultural landscape. Additionally, the sustainability of cultural landscape requires an integration of all stakeholders in the decision-making process [61]. As one of the stakeholders, however, the tourists' perception and understanding on the waterways are rarely mentioned. It needs further study to ultimately shape the adaptive management paths that are taken for the waterways of Hongcun.

Author Contributions: Conceptualization, P.C. and X.K.; methodology, P.C. and D.Z.; software, Y.Z.; validation, X.K.; formal analysis, P.C.; investigation, P.C. and D.Z.; resources, X.K.; data curation, D.Z. and X.K.; writing —original draft preparation, P.C.; writing—review and editing, Y.Z.; visualization, Y.Z.; supervision, X.K.; project administration, X.K.; funding acquisition, X.K. All authors have read and agreed to the published version of the manuscript.

Funding: This research is financially supported by the National Natural Science Foundation of China (Grant No. 41771156), China Scholarship Council Fund (File No. 202002370017), and ECNU Academic Innovation Promotion Program for Excellent Doctoral Students (YBNLTS2020-022).

Acknowledgments: We would like to thank Wang Ruihua, a local folklore expert of Hongcun Village, for the information that he provided. This paper was completed in Finland, and we would like to express our gratitude to Jarkko Saarinen at the University of Oulu and Olga Hannonen at the University of Eastern Finland for their valuable comments on an early draft. Thanks also to the six anonymous reviewers and Stefan Hotes and Tomohiro Ichinose, the guest editors of the special issue "Cultural Landscapes", for their generous and helpful suggestions in shaping this paper. All errors and omissions are our own.

Conflicts of Interest: The authors declare no conflict of interest.

\section{References}

1. Britton, S. Tourism, capital, and place: Towards a critical geography of tourism. Environ. Plan. D Soc. Space 1991, 9, 451-478. [CrossRef]

2. Terkenli, T.S. Tourism and landscape. In A Companion to Tourism; Lew, A.A., Hall, C.M., Williams, A.M., Eds.; Blackwell Publishing Ltd.: Malden, MA, USA, 2004; pp. 339-348.

3. Jiménez-García, M.; Ruiz-Chico, J.; Peña-Sánchez, A.R. Landscape and tourism: Evolution of research topics. Land 2020, 9 , 488. [CrossRef]

4. Yan, X.; He, S. The co-evolution of therapeutic landscape and health tourism in bama longevity villages, China: An actor-network perspective. Health Place 2020, 66, 102448. [CrossRef]

5. Ayala, H. Resort hotel landscape as an international megatrend. Ann. Tour. Res. 1991, 18, 568-587. [CrossRef]

6. Uysal, Ü.E. Urban Tourism in Istanbul: Urban Regeneration, Mega-Events and City Marketing and Branding; Publications of the Department of Social Research 2015: 6 Social and Public Policy: Helsinki, Finland, 2015.

7. Prokkola, E.K. Borders in tourism: The transformation of the Swedish-Finnish border landscape. Curr. Issues Tour. 2010, 13, 223-238. [CrossRef]

8. Terkenli, T.S. Landscapes of tourism: Towards a global cultural economy of space? Tour. Geogr. 2002, 4, 227-254. [CrossRef]

9. Rhoden, S.; Kaaristo, M. Liquidness: Conceptualising water within boating tourism. Ann. Tour. Res. 2020, 81, 102854. [CrossRef]

10. Kaaristo, M. Waterways and the cultural landscape. Tour. Geogr. 2019, 21, 192-194. [CrossRef]

11. Pitt, H. Review of waterways and the cultural landscape, edited by Francesco Vallerani and Francesco Visentin. Cult. Geogr. 2018. [CrossRef]

12. Cole, S.; Ferguson, L. Towards a gendered political economy of water and tourism. Tour. Geogr. 2015, 17, 511-528. [CrossRef]

13. Carse, A.; Lewis, J.A. Toward a political ecology of infrastructure standards: Or, how to think about ships, waterways, sediment, and communities together. Environ. Plan. A Econ. Space 2017, 49, 9-28. [CrossRef]

14. Vallerani, F. Flowing consciousness and the becoming of waterscapes. In Waterways and the Cultural Landscape; Vallerani, F., Visentin, F., Eds.; Routledge: Oxon, UK, 2018; pp. 1-16.

15. Guyer, C.; Pollard, J. Cruise visitor impressions of the environment of the Shannon-Erne waterways system. J. Environ. Manag. 1997, 51, 199-215. [CrossRef]

16. Markuksela, V; Valtonen, A. Dance with a fish? Sensory human-nonhuman encounters in the waterscape of match fishing. Leis. Stud. 2019, 38, 353-366. [CrossRef]

17. Verbrugge, L.; Buchecker, M.; Garcia, X.; Gottwald, S.; Müller, S.; Præstholm, S.; Olafsson, A.S. Integrating sense of place in planning and management of multifunctional river landscapes: Experiences from five European case studies. Sustain. Sci. 2019, 14, 669-680. [CrossRef]

18. Prideaux, B.; Cooper, M. River Tourism; CABI: Oxfordshire, UK, 2009. 
19. Hall, C.M.; Härkönen, T. Lake Tourism: An. Integrated Approach to Lacustrine Tourism Systems; Channel View Publications: Clevedon, $\mathrm{UK}, 2006$.

20. Duggan, M. Cruising landscape-objects: Inland waterway guidebooks and wayfinding with them. Cult. Geogr. 2021. [CrossRef]

21. Li, C.; Chen, H. Culture and nature in conserving the indigenous water system in rural China: A case study of the ancient village of Hongcun. J. Landsc. Archit. 2020, 15, 44-55. [CrossRef]

22. Crossley, É. Ecological grief generates desire for environmental healing in tourism after COVID-19. Tour. Geogr. 2020, 22, 536-546. [CrossRef]

23. Cheer, J.M. Human flourishing, tourism transformation and COVID-19: A conceptual touchstone. Tour. Geogr. 2020, 22, 514-524. [CrossRef]

24. Carr, A. COVID-19, indigenous peoples and tourism: A view from New Zealand. Tour. Geogr. 2020, 22, 491-502. [CrossRef]

25. Cristiano, S.; Gonella, F. 'Kill Venice': A systems thinking conceptualisation of urban life, economy, and resilience in tourist cities. Humanit. Soc. Sci. Commun. 2020, 7, 1-13. [CrossRef]

26. Prince, S. Dwelling and tourism: Embracing the non-representational in the tourist landscape. Landsc. Res. 2019, 44, 731-742. [CrossRef]

27. Visentin, F. Liquid conclusion: Towards a humanistic hydrology. In Waterways and the Cultural Landscape; Vallerani, F., Visentin, F., Eds.; Routledge: Oxon, UK, 2018; pp. 250-262.

28. Daugstad, K. Negotiating landscape in rural tourism. Ann. Tour. Res. 2008, 35, 402-426. [CrossRef]

29. Sauer, C.O. The morphology of landscape. Univ. Calif. Publ. Geogr. 1925, 2, 19-54.

30. Cosgrove, D. Landscape studies in geography and cognate fields of the humanities and social sciences. Landsc. Res. 1990, 15, 1-6. [CrossRef]

31. Brox, T. Landscapes of little Lhasa: Materialities of the Vernacular, political and Commercial in urban China. Geoforum 2019, 107, 24-33. [CrossRef]

32. Terkenli, T.S. Towards a theory of the landscape: The Aegean landscape as a cultural image. Landsc. Urban. Plan. 2001, 57, 197-208. [CrossRef]

33. Pitkänen, K. Second-home landscape: The meaning(s) of landscape for second-home tourism in Finnish Lakeland. Tour. Geogr. 2008, 10, 169-192. [CrossRef]

34. Waterton, E. More-than-representational landscapes. In The Routledge Companion to Landscape Studies, 2nd ed.; Howard, P., Thompson, I., Waterton, E., Atha, M., Eds.; Routledge: London, UK, 2019; pp. 91-101.

35. Anderson, K.; Domosh, M.; Pile, S.; Thrift, N. Handbook of Cultural Geography; Sage: London, UK, 2003.

36. Daniels, S.; Cosgrove, D. Introduction: Iconography and landscape. In The Iconography of Landscape: Essays on the Symbolic Representation, Design and Use of Past Environments; Cosgrove, D., Daniels, S., Eds.; Cambridge University Press: Cambridge, UK, 1988; pp. 1-10.

37. Thrift, N. It's the little things. In Geopolitical Traditions: A Century of Geopolitical Thought; Dodds, K., Atkinson, D., Eds.; Routledge: London, UK, 2000; p. 380.

38. Li, Q.J.; Cai, X.M. Literature review and analysis on landscape research from perspective of new cultural geography. Hum. Geogr. 2017, 32, 23-28. (In Chinese)

39. Owens, M. Waterways and the cultural landscape. Cult. Geogr. 2018, 35, 416-418. [CrossRef]

40. Wang, S.Q. Water Patterns in Hongcun Village: Tracing the Civil. History of the Living Environment in Hongcun Village; Jiangsu Art Press: Nanjing, China, 2004. (In Chinese)

41. Editorial Committee. Reading Huizhou; University of Science and Technology of China Press: Hefei, China, 2015. (In Chinese)

42. Wang, Q.M. Heavenly Huizhou; China Federation of Literary and Art Publishing House: Beijing, China, 2006. (In Chinese)

43. Chen, X.D. The Analysis and Research about Rational Use of Water Resources in Traditional Village. Master's Thesis, Hefei University of Technology, Hefei, China, 2010. (In Chinese)

44. Bao, J.G. Monitoring Report on China Tourism Sustainable Development Monitoring Base of UNWTO (2014-2016); China Travel Publishing House: Beijing, China, 2018. (In Chinese)

45. Macpherson, H. Non-representational approaches to body-landscape relations. Geogr. Compass 2010, 4, 1-13. [CrossRef]

46. Jones, O. Geography, memory and non-representational geographies. Geogr. Compass 2011, 5, 875-885. [CrossRef]

47. Maclaren, A.S. Rural geographies in the wake of non-representational theories. Geogr. Compass 2019, 13, e12446. [CrossRef]

48. Dewsbury, J.D. Non-representational landscapes and the performative affective forces of habit: From 'Live' to 'Blank'. Cult. Geogr. 2015, 22, 29-47. [CrossRef]

49. Hassan, A.; Ramkissoon, H.; Shabnam, S. Community resilience of the Sundarbans: Restoring tourism after oil spillage. J. Hosp. Tour. 2017, 15, 1-18.

50. Imperiale, A.J.; Vanclay, F. Experiencing local community resilience in action: Learning from post-disaster communities. J. Rural Stud. 2016, 47, 204-219. [CrossRef]

51. Saarinen, J. Critical sustainability: Setting the limits to growth and responsibility in tourism. Sustainability 2014, 6, 1-17. [CrossRef]

52. Sheppard, V.A.; Williams, P.W. Factors that strengthen tourism resort resilience. J. Hosp. Tour. Manag. 2016, 28, 20-30. [CrossRef]

53. Amore, A.; Prayag, G.; Hall, C.M. Conceptualizing destination resilience from a multilevel perspective. Tour. Rev. Int. 2018, 22, 235-250. [CrossRef] 
54. Seraphin, H.; Sheeran, P.; Pilato, M. Over-tourism and the fall of Venice as a destination. J. Destin. Mark. Manag. 2018, 9, 374-376. [CrossRef]

55. Cheer, J.M.; Milano, C.; Novelli, M. Tourism and community resilience in the Anthropocene: Accentuating temporal overtourism. J. Sustain. Tour. 2019, 27, 554-572. [CrossRef]

56. Head, L. Conceptualising the human in cultural landscapes and resilience thinking. In Resilience and the Cultural Landscape: Understanding and Managing Change in Human-Shaped Environments; Plieninger, T., Bieling, C., Eds.; Cambridge University Press: Cambridge, UK, 2012; pp. 65-79.

57. Prager, K. Collective efforts to manage cultural landscapes for resilience. In Resilience and the Cultural Landscape: Understanding and Managing Change in Human-Shaped Environments; Plieninger, T., Bieling, C., Eds.; Cambridge University Press: Cambridge, UK, 2012; pp. 205-223.

58. Musavengane, R.; Kloppers, R. Social capital: An investment towards community resilience in the collaborative natural resources management of community-based tourism schemes. Tour. Manag. Perspect. 2020, 34, 100654. [CrossRef]

59. Plieninger, T. Connecting cultural landscapes to resilience. In Resilience and the Cultural Landscape: Understanding and Managing Change in Human-Shaped Environments; Plieninger, T., Bieling, C., Eds.; Cambridge University Press: Cambridge, UK, 2012; pp. 3-26.

60. Fatimah, T. The impacts of rural tourism initiatives on cultural landscape sustainability in Borobudur area. Procedia Environ. Sci. 2015, 28, 567-577. [CrossRef]

61. Heslinga, J.; Groote, P.; Vanclay, F. Towards resilient regions: Policy recommendations for stimulating synergy between tourism and landscape. Land 2020, 9, 44. [CrossRef] 